\title{
Research on the Teaching of Numerical Analysis for Postgraduates
}

\author{
Minghui Wang, Yinhuan Han* \\ School of Mathematics \& Physics, Qingdao University of Science \&Technology, Qingdao, Shandong 266061, China \\ *Corresponding author. Email:02913@qust.edu.cn
}

\begin{abstract}
Teaching process of numerical analysis for non-mathematics graduate students shows some characteristics and problems. In consequence, authors analyze and study the teaching process from their teaching experience in the past three years. They present some teaching methods and models which are able to improve the quality of teaching effectively. The methods use an online-to-offline hybrid model to solve conflict between less course time and more content, and difference cognitively among students. By applying numerical analysis approaches in mathematical modeling, these teaching methods stress importance of numerical analysis to students. As result, the presented teaching methods achieve the aims of stimulating the initiative of students and enhancing the quality of teaching.
\end{abstract}

Keywords: Numerical analysis, Teaching method, Teaching effect, Mathematical modelling.

\section{INTRODUCTION}

Numerical Analysis is a branch of mathematical science. It aims to studies the numerical calculation methods. Numerical analysis theory and software realization can solve various mathematical problems. It expresses a mathematical problem in form of equation to solve the problem with arithmetic and logical operations [1]. Numerical analysis is an important basic course for master of science and engineering. It contains theory, experiment and computational science three pillars of scientific research. Through study of numerical analysis, students can not only have certain mathematics algorithm theory and application ability, but also train the student's scientific quality in the future. Besides, this course develop students' innovative consciousness and improve their innovative ability. With development of computers, the use of numerical analysis in solving engineering and scientific problems is exploding. It is to be a part of every engineer and scientist's basic education. Therefore, it is very important to explore the improvement of teaching method in numerical analysis course for improving student's applying mathematics ability.

Based on education target and teaching process, we present some teaching methods for improving the quality of teaching, and reform the teaching methods. In past three years, numerical analysis teaching team have studied the teaching theories and accumulated the teaching practical experiences. As a result, we have summarized some existing problems in the teaching of the numerical analysis course for non-mathematical postgraduates, and give some approaches to solved the problems.

\section{FEATURES OF THE COURSES}

\subsection{Wide Coverage in Teaching Content}

Numerical analysis course mainly includes[1]: numerical approximation of function, numerical differentiation and numerical integration, numerical solution of system of linear equations, roots finding of the nonlinear equation, numerical linear Algebra, numerical solutions of the ordinary differential equation. These contents involve solving practical problems of meteorology, mechanics, physics, biology, engineering technology, economics and so on. The course covers a wide range of mathematical disciplines including advanced mathematics, linear algebra, differential equation, and many other scientific fields.

\subsection{Abstraction and Scientificity}

The content of numerical analysis course is not only highly abstract, rigorous theoretical and logical, but also extensive in application, technical and approximate in practical experiment. In other words, numerical analysis is applied course with close relation between theory and 
practice. The course contents of numerical analysis are all produced to solve practical problems, so the contents of the course have extensive application requirements and practical applications.

\subsection{Various Algorithms}

The contents of numerical analysis are various, and algorithms are complex. The algorithms are independent of each other logically. Therefore, it is easy for teaching and learning. For non-mathematics major graduate students, their knowledge structure is relatively well-developed. It should be easy to understand practical problems for the students. However, they are weak on mathematical derivation so that problem solving becomes hard for them. All the algorithms in this course can be programmed on the computer. With the development of computing technology and science technology, the algorithms of numerical analysis are not only developing explosively in the application of engineering and scientific problem solving, but also playing an increasingly important role in more and more fields. It became an important part in the scientific basic education.

\subsection{Method Application}

Although some methods' theories in numerical analysis are same with the theories in advanced mathematics, the numerical analysis emphasizes that how to use these theories to calculate reasonable results. For example, Newton's iterative formula for solving the roots of nonlinear equations is an application of Taylor's formula in higher mathematics; the error analysis of the polynomial interpolation method uses the mean value theorem and the zero theorem in higher mathematics; Square root method, which takes the symmetric positive definite matrix as the system of linear equations of the coefficient matrix, uses matrix decomposition theory in linear algebra.

\section{WHY STUDY NUMERICAL ANALYSIS}

When some students take this course, the two most frequently asked questions are: "why they take the course?" and "What is the course used for?". Minghui Wang et al summarized some explanations in the numerical analysis textbook. Hereon, we only emphasize two aspects [1].

\subsection{Ability Improvement for Solving Practical Problems}

The numerical methods can solve the problem of solving large system of linear equations, nonlinear and complicated geometry problems which are common in engineering and science applications. However, the standard analytical methods are limited to solve the problems which have exact solution. Therefore, learning of numerical analysis can enhance the skills of problem solving in engineering fields.

\subsection{Improvement of the Understanding and Cognition for Mathematical Problems}

Numerical analysis provides a platform to enhance the understanding of mathematics. One function of numerical methods is to transform mathematics from a high-level representation to a basic arithmetic operation. This unique perspective can improve the understanding and cognition of mathematical problems.

\section{PROBLEMS IN NUMERICAL ANALYSIS COURSE}

\subsection{Less Course Time}

As common course, the numerical analysis for graduate student only has about 32 class hours in most universities. Since the course has too many contents and complex algorithms, the class hours are relatively insufficient. Less class time brings great difficulty to organize of teaching content and design of teaching content explanation. because the class size is nearly 150 , It's difficult to effectively carry out classroom discussion and communication. Teachers cannot explain so many algorithms within a short time. Effective teaching methods should be suggested. Meanwhile, students should also take initiative to explore suitable learning methods to improve learning efficiency. Twopronged approach to be achieved for the best state of learning.

\subsection{Inadequate Practice}

Based on the characteristics of this course, to achieve the application of knowledge, computer practice is necessary. In fact, less class hours do not allow us to lead students to carry out practical operations with computer programming. Students can't grasp the algorithm. Less class hours lead to less practice. Students cannot improve their experimental operation 
ability with computer programming. Also, Students lack analysis ability about experimental results with mathematical knowledge. Furthermore, students cannot effectively improve the typical algorithms for specific problems.

\subsection{Different Learning Ability}

The graduate students always are from different universities and different majors. Some of them are from engineering majors and others are from nonengineering cmajors. Therefore, the mathematics knowledges of students have greater difference. It brings greater difficulty for course teaching. To learn numerical analysis effectively, students must have basic knowledge of mathematics such as advanced mathematics, linear algebra and differential equation. However, some students, who are form junior college, have no knowledges about differential equations. It is very difficult for teachers of numerical analysis to teach numerical solutions of differential equations. Teachers have to start from differential equations one more time.

\section{IMPROVEMENT OF TEACHING METHODS}

\subsection{Use of Teaching Platform}

To solve conflict between less course time and more content, and difference cognitively among students, we have used the superstar teaching platform in this year. In the platform, teachers publish classroom courseware, teaching video, extended materials, chapter tests, homework and so on to satisfy different requirements from students. The students, who could not understand the course content completely, have a way to learn the course content ago using the learning materials in the platform, the other students can review the course content. Furthermore, extended materials make students to expand their study range. By the end of the semester, more than 90 percent of the students were satisfied with the online-to-offline blended education, and their final grades were a higher than past few semester, with a 100 percent pass rate. Online and offline blended learning model is also very helpful for underperforming, reserved students in the classroom, who tend to be in the middle of the class. They can learn freely online without any burden; they can ask all kinds of questions on the learning platform. They are more and more interested in the study of numerical analysis through the teacher's online explanation. The online and offline hybrid teaching method effectively improves study efficiency of middle students, also improves overall academic performance. The Figure 1 shows the teaching videos in platform.

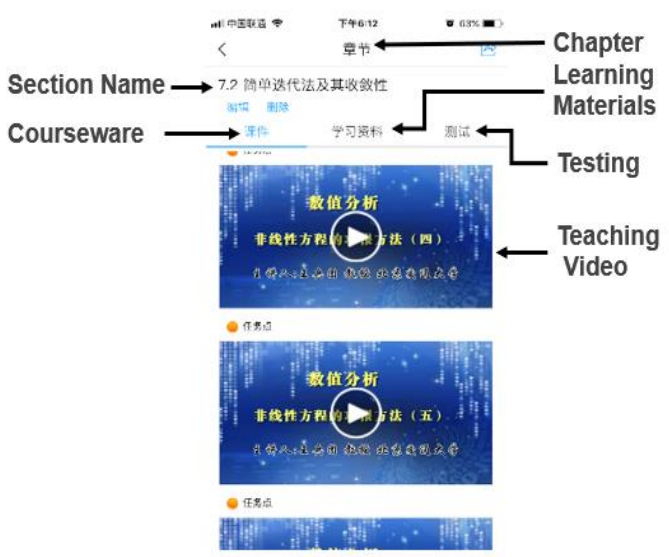

Figure 1 Teaching Video in Superstar Platform.

\subsection{Visualized Teaching}

Due to the lack of class hours, computer practice can't be carried out. We make up it by using visual teaching method. For example, teachers could choose a typical and simple instance in class (solving the root problem of a simple nonlinear equation with a Newton's method) and explain to students how to write the program on the computer[4]. It makes students experience programing process in a short class time, and effectively improve programming ability. It was found that students prefer this kind of visual teaching method. In general, graduate students spend most of their time in major courses. The no-major courses tend to be discounted. Less time is spent on no-major course. Therefore, the visualized teaching get better practice result. At the same time, students are encouraged to participate in scientific research activities. The students would realize the wide application of numerical analysis in various fields.

\subsection{Integrated with Mathematical Modelling}

We have integrated some mathematical modelling [5] which are related to the theory and method of numerical analysis into this course. It can catch students' attention easily, and train practical ability of students. Meanwhile, enhance student's consciousness of analysing and researching problems with mathematical knowledge. By introducing mathematical modelling into 
numerical analysis, more than 55 percent of nonmathematical graduate students have started to pay more attention on numerical analysis. Students' active learning in classroom. Some of them are very enthusiastic about algorithm analysis and do some computer experiments. Because the problem of mathematical modelling generally comes from the practical problems in engineering technology or physics, and the processes of establishing, solving and applying for mathematical modeling is a combination of disciplines in various fields, therefore, mathematics modelling can reflect teacher's teaching level and scientific research ability. From the student's point of view, it is a way to study mathematics knowledge, cultivate application ability and improve innovation quality. All the past graduate students, who have learned the subject of numerical analysis, have advantages on mathematical modelling.

In 2019, one of our graduate students won the first prize in the National Mathematical Modelling Competition, an increase one over 2018; 22 students won Second Prize, an increase of six over 2018; and 35 students won the third prize, an increase of 10 from 2018. The idea of modelling is integrated into the course of numerical analysis for graduate students. The students known that how to solve practical problems using mathematical knowledge. these students also are benefited from Mathematical Modelling Training Program, which further taught a detailed content of numerical analysis related to mathematical modelling. whether it is to establish the mathematical model of the practical problem or to find the algorithm to solve the modelling problem, there were Flexible and varied methods. Numerical analysis can provide Sufficient theoretical basis and many practical applications. Since students actually benefit from studying numerical analysis, more students will pay more attention on this public course in the future. According to the principles of reaction, teachers will also be more motivated to research teaching methods. At last we look forward to achieving the best teaching results in the future.

\section{CONCLUSION}

Based on the characteristics of this course and some deficiencies in teaching, the authors analyses problems in numerical analysis teaching process. And suggest two approaches in the aspects of teaching methods and teaching ideas. First approach combines the online and offline mixed mode with the visual teaching method. Second approach applies the mathematical modeling in teaching process. The approaches have been applied in last semester. The approaches already shown some effects on teaching result. However, teaching effect improvement is a long-term subject. It is necessary to continuously study and improve the teaching plan and carry out teaching practice for finding the best teaching mode. Teacher should try their best to excite students' interest. Effective ways are: Careful teaching design, students' active participation in teaching, helping each other, cooperative learning, multiple ways of evaluation.

\section{AUTHORS' CONTRIBUTIONS}

Yinhuan Han contributed to the conception of the study;

Yinhuan Han and Minghui Wang performed the experiment;

Yinhuan Han performed the data analyses and wrote the manuscript;

Minghui Wang helped perform the analysis with constructive discussions.

\section{ACKNOWLEDGMENT}

This paper was supported by the Graduate Education Excellent Course Project (No. SDYKC17038) and Professional Degree Graduate Teaching Case Database Project (No. SDYAL18063) in Shandong Provincial.

\section{REFERENCES}

[1] M.H. Wang, G.B.Wang, W.Zhang, Apllied Numerical Analysis, Chemical Industry Press, 2015. (In Chinese)

[2] G.C.Li, Method of Calculation ( $3^{\text {rd }}$ edition), Publishing House of Electronics Industry, 2019. (In Chinese)

[3] X. Chen, S.B. Qu, F. Liu, Numerical Analysis, Publishing House of Electronics Industry, 2019. (In Chinese)

[4] J. Zuo, Discussion and Practice on Teaching Reform of the Numerical Analysis Course, Education and Teaching Forum, 2020, pp. 187-188. (In Chinese)

[5] J. Guo, C.D. Wei, Research and Practice of Mathematical Modelling in Numerical Analysis Teaching, Journal of Guangxi Teachers Education University (Natural Science Edition), 2008, pp. 124-127. (In Chinese) 